Journal of Engineering and Applied Sciences 14 (21): 7943-7950, 2019

ISSN: 1816-949X

(C) Medwell Journals, 2019

\title{
Modeling Average Prices of Garlic in Indonesia
}

\author{
${ }^{1}$ Agus Widodo, ${ }^{2}$ Heni Kusdarwati and ${ }^{2}$ Samingun Handoyo \\ ${ }^{1}$ Department of Mathematics, \\ ${ }^{2}$ Department of Statistics, Faculty of Science, Brawijaya University, Malang, Indonesia
}

\begin{abstract}
The high consumption of garlic in Indonesia cannot be followed by an adequate supply of garlic, so that, until now Indonesia still imports garlic. Policy formulation in the field of essential goods requires accurate information The study discusses modeling stages and develops of the average prices of garlic in Indonesia with the ARIMA Box-Jenkins method. The monthly data of average prices of garlic in the January 2014 to June 2018 period obtained from the directorate of basic goods and essential goods of the Ministry of Trade of the Republic of Indonesia. Model development uses data from the period of January 2014 to December 2017 which were referred to as in-sample data while data from January 2018 to June 2018 period as out-sample data to evaluate model performance. Modeling begins with the transformation of time series data into stationary time series data, identification pattern of common models via. plot of $\mathrm{ACF}$ and $\mathrm{PACF}$ values, estimating and testing of parameters to obtain a feasible model, then continued with a model diagnostic test and finally, gets the best model is ARIMA Model $(1,1.0)$. Based on the best model, the comparison plot was made between the actual and predicted values that were resulted by both of in-sample and out-sample data and also was calculated the coefficient of determination $\left(\mathrm{R}^{2}\right)$ as accuracy measure. The actual and predicted values plot in the in-sample data are very coincident and produce $\mathrm{R}^{2}$ which is quite high at $91.4 \%$. However, the performance of the ARIMA $(1,1,0)$ Model is moderate when forecasting out-sample data whicch $\mathrm{R}^{2}$ is $59.8 \%$.
\end{abstract}

Key words: Garlic price, ARIMA Model, forecasting, time series, ACF, PACF

\section{INTRODUCTION}

One of the staple goods which is always monitored and managed by the Directorate General of Domestic Trade of the Republic of Indonesia (Directorate General of PDN RI) in particular the directorate of basic needs and essential goods is garlic. Garlic is one of the basic needs commonly used for cooking food. In everyday life, garlic is consumed by almost all Indonesian people both in urban and rural areas. Unfortunately, the consumption of high garlic is not followed by an adequate supply. This is caused by less suitable land, weather and climate factor and the difficulty of finding the right seeds which Indonesian farmers are accustomed to planting local seeds and not believing in imported seeds. Therefore, until now Indonesia has not been able to independently fulfill the needs for garlic and still import garlic. The largest import of garlic came from China (Anonymous, 2017).

Indonesia's dependence on garlic-producing countries such as China has caused garlic prices in Indonesia to depend on imported garlic. The average prices of garlic in Indonesia from January 2014 to June 2018 tend to increase and also, fluctuate. The right policy formulation in the field of essential goods and essential foods, then there will be price stabilization which ends the community will benefit (Anonymous, 2018). Accurate and timely information support will be absolutely necessary to produce wise policy. Statistics modeling has an important role to produce accurate forecast values.

The availability of time series data on the average prices of garlic per month in the period January 2014 to June 2018, inspired the researcher to do ARIMA modeling in order to obtain accurate forecast values. Some researchers have successfully applied the ARIMA Model in various fields, namely forecasting prices and productivity of the construction industry in Singapore by Hua and Pin (2000), Tan et al. (2010) improving daily electricity prices using a combination of wavelets and ARIMA-GARCH while improving accuracy forecasting on annual runoff data with the ARIMA method by Wang et al. (2015). Many researchers also, compare performance and hybridization between ARIMA methods and neural networks including Ho et al. (2002) and Zhang (2003). Even, Rojas et al. (2008) applied soft-computing method and Handoyo et al. (2017) applied particle swarm optimization for estimating ARIMA Model parameters. Even recently, Kusdarwati and Handoyo (2018) used the identification inputs of a hybrid model of wavelet and neural networks based on identification from the ARIMA Model, the same research was done by Handoyo and Marji (2018) as input of fuzzy inference systems. Some of the above studies show that the modeling of time series

Corresponding Author: Agus Widodo, Department of Mathematics, Faculty of Science, Brawijaya University, Malang, Indonesia 
data is rooted in the ARIMA method which has a structured stage of the modeling process, so that, it is easy to apply.

\section{MATERIALS AND METHODS}

A process can be said to be a stationary process, if it produces a mean and variance constant at the same interval time of observation. According to Cryer and Kung-Sik (2008), stationarity is an important assumption in inferential statistics. Stationary in the time series means that the data remains constant throughout the time of observation. If a time series data is stationary, data fluctuations will be around a constant mean value.

Variation fluctuations can be seen visually through time series data plot. If the fluctuations of the variance in time series data are not too large (homogeneous), the time series data is said to have been. stationary against the variance. Box-Cox transformation is a method for checking stationary variance in a time series data (Wei, 2006). If the value of $\lambda=1$ then the data is stationary to the variance and if the value of $\lambda$ is not the same as 1 then the data is transformed by raising the data with the value $\lambda$ obtained in the Box-Cox plot. Stationary against mean testing can be done using the Augmented Dickey-Fuller unit root test. Cryer and Kung-Sik (2008) facilitates the notion of unit root testing by looking at the $\mathrm{AR}(1)$ Model as follows:

$$
\begin{aligned}
\mathrm{Y}_{\mathrm{t}}-\mathrm{Y}_{\mathrm{t}-1} & =(\alpha-1) \mathrm{Y}_{\mathrm{t}-1}+\mathrm{X}_{\mathrm{t}-1} \\
& =\mathrm{a} \mathrm{Y}_{\mathrm{t}-1}+\phi_{1} \mathrm{X}_{\mathrm{t}-1}+\ldots,+\phi_{\mathrm{k}} \mathrm{X}_{\mathrm{t}-\mathrm{k}}+\mathrm{e}_{\mathrm{t}} \\
& =\mathrm{a} \mathrm{Y}_{\mathrm{t}-1}+\phi_{1}\left(\mathrm{Y}_{\mathrm{t}-1}-\mathrm{Y}_{\mathrm{t}-2}\right)+\ldots,+\phi_{\mathrm{k}}\left(\mathrm{Y}_{\mathrm{t}-\mathrm{k}}-\mathrm{Y}_{\mathrm{t}-\mathrm{k}-1}\right)+\mathrm{e}_{\mathrm{t}}
\end{aligned}
$$

Based on Eq. 1 above, the hypothesis used in testing stationary against mean with the roottest of Augmented Dickey-Fuller unit is:

- $\mathrm{H}_{0}: \alpha=0$ (time series is not stationary against mean) vs.

- $\mathrm{H}_{1}: \alpha<0$ (stationary time series against mean)

If the time series data is not stationary against the mean, the differentiation process is done until the time series that is stationary against the mean. The steps in modeling the ARIMA (p, $\mathrm{d}, \mathrm{q})$ in general are as follows:

Model identification: According to Wei (2006), most time series data are not stationary while the autoregressive (p) and moving average (q) determinations in ARIMA modeling can only be done on stationary data. Determination of the p order is done by looking at the PACF plot while determination the $\mathrm{q}$ order is done by looking at the ACF plot. According to Cryer and Kung-Sik (2008), the general characteristics of ACF and PACF for the ARIMA Model with a degree of difference equal to $0(\mathrm{~d}=0)$ can be seen in Table 1 .

Parameter estimation and significance testing: According to Cryer and Kung-Sik (2008), there are several methods for estimating of parameter in a model including method of moment, least square estimation, maximum likelihood and unconditional least square. Properties of the estimates, illustrations of parameter estimation and bootstrapping of ARIMA Models. Handoyo et al. (2007) estimated the parameter of ARMA Model using Particle Swarm Optimization (PSO) method which resulted in parameter estimator values which were not significantly different is compared parameter estimator values by the ordinary least square or maximumlikelihood method.

The parameter estimation method commonly be used is the maximum likelihood method. According to Wei (2006), the log-likelihood function for ARIMA (p, q) can be written as follows:

$$
\begin{aligned}
\ln L\left(\phi, \mu, \theta, \sigma_{\mathrm{a}}^{2}\right) & =-\frac{\mathrm{n}}{2} \ln \left(2 \pi \sigma_{\mathrm{a}}^{2}\right)-\frac{\mathrm{S}(\phi, \mu, \theta)}{2 \sigma_{\mathrm{a}}^{2}} \\
\ln \mathrm{L}\left(\phi, \mu, \sigma_{\mathrm{a}}^{2}\right) & =-\frac{\mathrm{n}}{2} \ln \left(2 \pi \sigma_{\mathrm{a}}^{2}\right)-\frac{\mathrm{S}\left(\phi_{1}, \mu\right)}{2 \sigma_{\mathrm{a}}^{2}}
\end{aligned}
$$

To obtain the value $\hat{\mu}$, the log-likelihood function for AR (1) in Eq. 2 is maximized by differences of partial and finally, the estimator parameters $\mu$ as follows:

$$
\frac{\partial \ln L\left(\phi_{1}, \mu, \sigma_{a}^{2}\right)}{\partial \mu}=\frac{\sum_{\mathrm{t}=\mathrm{p}+1}^{\mathrm{n}} 2\left[\left(\mathrm{Y}_{\mathrm{t}}-\mu\right)-\phi_{1}\left(\mathrm{Y}_{\mathrm{t}-1}-\mu\right)\right]\left(-1+\phi_{1}\right)}{-2 \sigma_{\mathrm{a}}^{2}}
$$

So that, $\hat{\mu}$ can be calculated using Eq. 3 below:

$$
\hat{\mu}=\frac{1}{(n-1)\left(1-\phi_{1}\right)}\left[\sum_{t=p+1}^{n} Y_{t}-\phi_{1} \sum_{t=p+1}^{n} Y_{t-1}\right]
$$

In addition, in order to obtain a value of $\hat{\phi}_{1}$ then the log-likelihood function for AR (1) in Eq. 2 is maximized by partial differences against the parameters $\phi_{1}$ to be expected to be as follows:

\begin{tabular}{llll}
\hline Process & AR $(p)$ & MA $(q)$ & ARIMA ( $p, q) ; p, q>0$ \\
ACF & Decreases exponentially or sine wave & Disconnected after the $q$-lag & Decreases exponentially or sine wave \\
PACF & Disconnected after the $p$-lag & Decreases exponentially or sine wave & Decreases exponentially or sine wave \\
\hline
\end{tabular}




$$
\begin{aligned}
& \frac{\partial \ln L\left(\phi_{1}, \mu, \sigma_{a}^{2}\right)}{\partial \phi_{1}}=\frac{\sum_{t=p+1}^{n} 2\left[\left(Y_{t}-\bar{Y}\right)-\phi_{1}\left(Y_{t-1}-\bar{Y}\right)\right]\left(-Y_{t-1}+\bar{Y}\right)}{-2 \sigma_{a}^{2}} \\
& \frac{\partial \ln L\left(\phi_{1}, \mu, \sigma_{a}^{2}\right)}{\partial \phi_{1}}=\frac{\sum_{t=p+1}^{n} 2\left[\left(Y_{t}-\bar{Y}\right)-\hat{\phi}_{1}\left(Y_{t-1}-\bar{Y}\right)\right]\left(Y_{t-1}-\bar{Y}\right)}{-2 \sigma_{a}^{2}}=0 \\
& \frac{\partial \ln L\left(\phi_{1}, \mu, \sigma_{a}^{2}\right)}{\partial \phi_{1}}=\sum_{t=p+1}^{n} 2\left[\left(Y_{t}-\bar{Y}\right)-\hat{\phi}_{1}\left(Y_{t-1}-\bar{Y}\right)\right]\left(Y_{t-1}-\bar{Y}\right)=0
\end{aligned}
$$

So that, if Eq. 4 is simplified, it can be calculated using the following equation:

$$
\hat{\phi}_{1}=\frac{\sum_{t=p+1}^{n}\left(Y_{t}-\bar{Y}\right)\left(Y_{t-1}-\bar{Y}\right)}{\sum_{t=p+1}^{n}\left(Y_{t-1}-\bar{Y}\right)^{2}}
$$

Parameter significance testing aims to determine the parameters that can be included in a model with the t-test statistics as follows:

$$
t=\frac{\hat{\theta}_{q}}{\operatorname{se}\left(\hat{\theta}_{q}\right)} \sim t_{n-q}
$$

The testing criteria used is if $t>t(\alpha / 2, n-q)$ then reject $\mathrm{H}_{0}$. In addition, the testing criteria that can also be used is comparing the p-value with the real level used $(\alpha)$. Reject $\mathrm{H}_{0}$, if the $\mathrm{p}<\alpha$ means the parameter in the model is significant at the significance level of $\alpha$.

Diagnostic testing of model: After estimating of the parameters, then only the models with significant parameter values will be diagnostic to find out the feasibility of model. Diagnostic testing of the model can be done in three ways, namely by the Ljung-Box test, identifying the ACF residual plot in white noise and the normality of the test. According to Wei (2006), the value of the residual (error) generated after ARIMA modeling is expected to be only a random disturbance. Therefore, if the autocorrelation has been obtained, it is expected that there will be no significant autocorrelation. The feasibility of the model can be tested using the Ljung-Box test with the $Q$ statistics as follows:

$$
\mathrm{Q}=\mathrm{n}(\mathrm{n}+2) \sum_{\mathrm{j}=1}^{\mathrm{k}} \frac{\hat{\rho}_{\mathrm{k}}^{2}}{(\mathrm{n}-\mathrm{k})} \sim \chi_{\mathrm{k}-\mathrm{m}}^{2}
$$

According to Cryer and Kung-Sik (2008), if the value of ${ }^{Q<x_{i}^{2}-m}$ where $m$ is the number of parameters estimated, results in a decision to accept $\mathrm{H}_{0}$. In addition, the testing criteria that can be used is by comparing the p-value with the significance level used $(\alpha)$. Accept $\mathrm{H}_{0}$, if the $\mathrm{p} \geq \alpha$ that means the ARIMA Model is suitable for forecasting.
Measures of model accuracy: A model can be said to have a high accuracy, if the model can predict the actual values by producing the predicted values with the small gap. Therefore, a calculation method is needed how it can produce a value which can describe the accuracy of the model. One method that can be used in measuring the accuracy of a model is the coefficient of determination $\left(\mathrm{R}^{2}\right)$. According to Handoyo and Marji (2018), the coefficient of determination can be calculated by using equation as follows:

$$
\mathrm{R}^{2}=\frac{\sum\left(\hat{\mathrm{y}}_{\mathrm{i}}-\overline{\mathrm{y}}\right)^{2}}{\sum\left(\mathrm{y}_{\mathrm{i}}-\overline{\mathrm{y}}\right)^{2}} ; 0 \leq \mathrm{R}^{2} \leq 1
$$

If the coefficient of determination $\left(\mathrm{R}^{2}\right)$ gets closer to one, the better the match of the data with the model or in other words the predicted values are very close to atual values. Whereas if the coefficient of determination $\left(R^{2}\right)$ is closer to zero, then the worse of the data matching with the model or in other words the predicted values are almost incorrect. The coefficient of determination $\left(\mathrm{R}^{2}\right)$ is more often presented in percentage form, meaning that the percentage of the total diversity of data can be explained by the model used while the residual may be due to other factors that fail to be taken into account in the model.

\section{RESULTS AND DISCUSSION}

In this study, a model will be built from data of the average price of garlic in Indonesia from January 2014 to June 2018 which is presented in Fig. 1.

The information that can be obtained from the time series data plot in Fig. 1 is the average price of garlic in Indonesia tends to fluctuate. The average price of garlic in Indonesia has increased from September 2015 to May 2016. In addition, starting in June 2017 there was a decrease in the average price of garlic in Indonesia until around the end of 2017. To model the average price of garlic in Indonesia, the data will be divided into two parts, namely in-sample data and out-sample data. In-sample data is the average price of garlic in Indonesia from January 2014 to December 2017 while the out-sample data is the average price of garlic in Indonesia from January 2018 to June 2018. In-sample data is used to build the model (curve fitting) while the out-sample data will be used as a model performance test in forecasting.

Before identifying the ARIMA Model, data must be stationary in terms of both variance and mean. Based on the time series data plot in Fig. 1, it indicates that the data is not stationary on variance and mean. To form stationary data on the variance, the Box-Cox transformation is performed with $\lambda=-1$ against all datum in the in-sample data. The following is the Box-Cox chart after being transformed. 


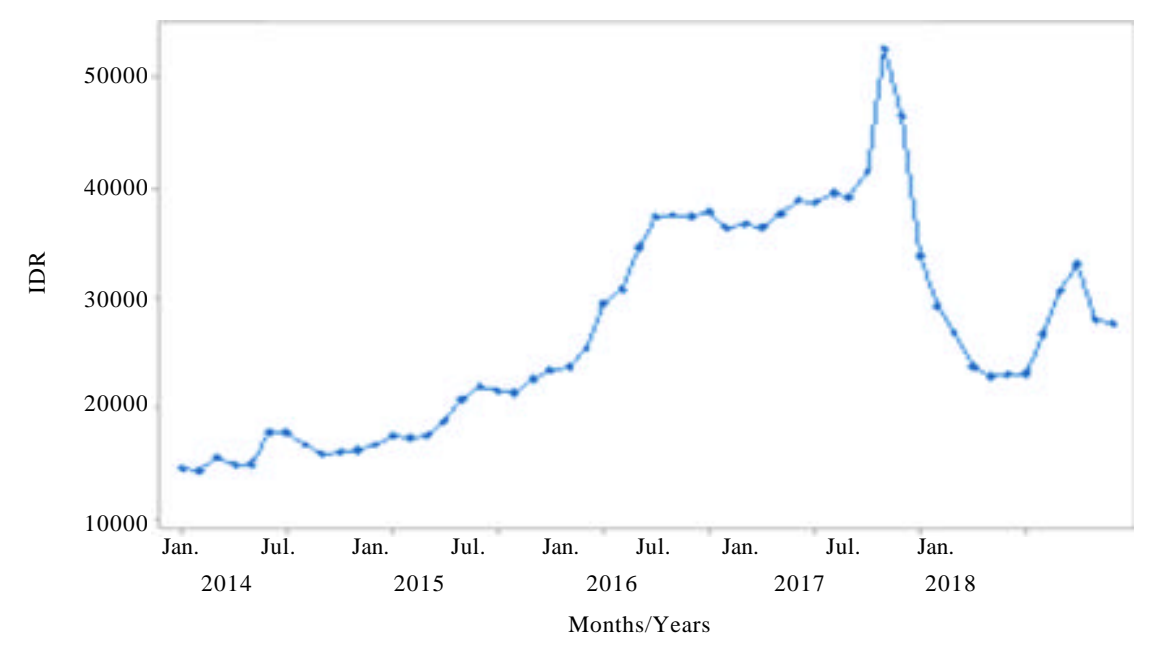

Fig. 1: Plot of average garlic prices in Indonesia (Anonymous, 2017)

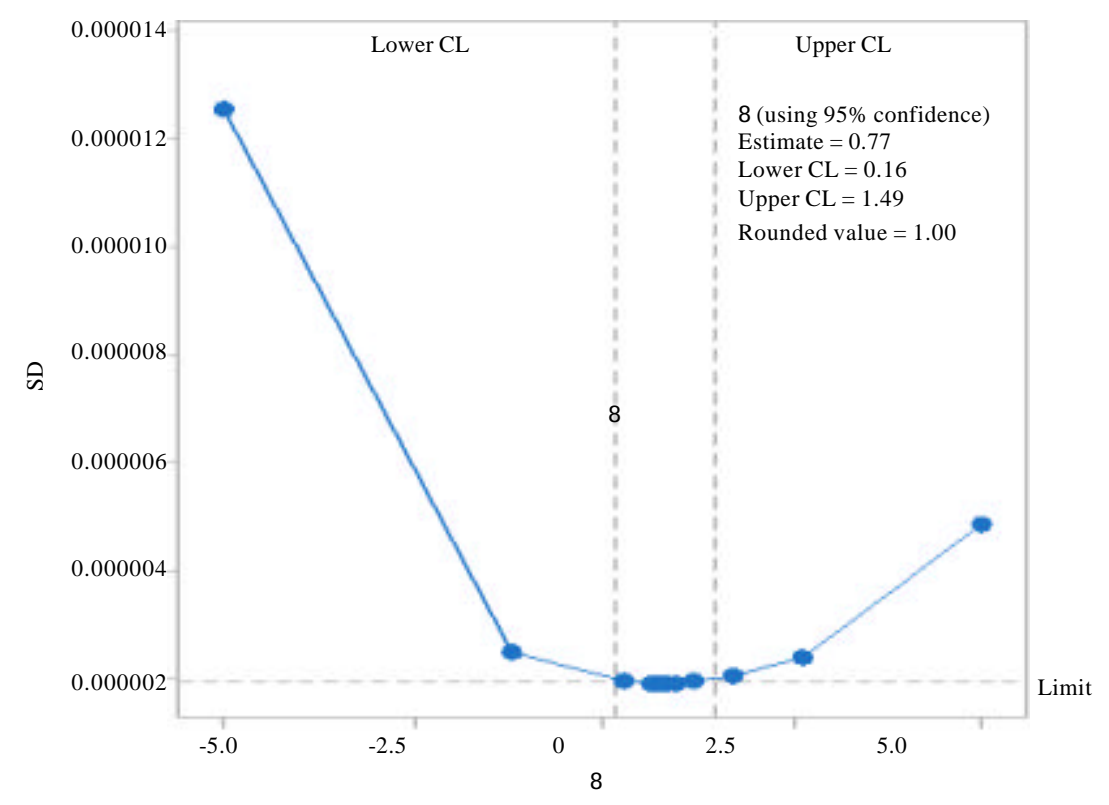

Fig. 2: Plot Box-Cox for in-sample data after transformation with $\lambda=-1$

From the Box-Cox plot in Fig. 2, we get a $\lambda$ value of 1 . Thus, it can be concluded that after the transformation is done by lifting the entire datum by -1 , the in-sample data has been stationary in the variance. Because the insample data is not stationary in the mean, then the first differencing is done, then a correlogram analysis is made through the Auto Correlation Function (ACF) plot and the Augmented Dickey-Fuller unit root test. The following is ACF plot results for in-sample data after the first differencing.

Based on the ACF plot in Fig. 3, it appears that the autocorrelation is only significant (out of the confidence limit) in the first lag. Therefore, it can be concluded that the in-sample data has been stationary against the mean after the first differencing. To be more convincing about the results of the correlogram analysis, then the root test of the Augmented Dickey-Fuller unit was carried out. It shows that the p-value is close to zero on both lag 0 and 1 and the result of p-value is 0.0108 in lag 2 . Because the $\mathrm{p}$-value of all the lags is smaller than $\alpha=0.05$, it results in a decision that there is no unit root in the in-sample data after the first differencing. Thus, it can be concluded that the in-sample data is stationary against the mean after the first differencing. 


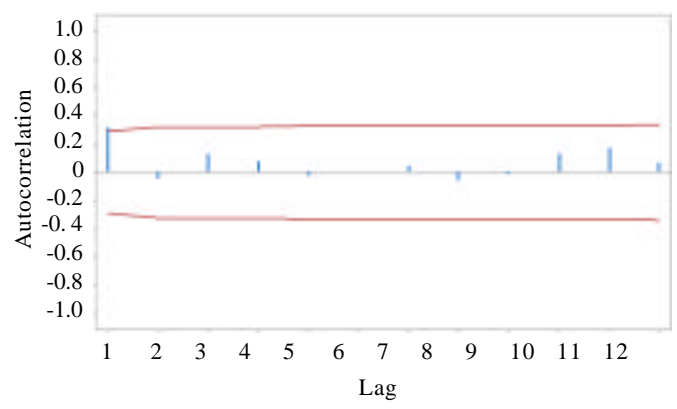

Fig. 3: Autocorrelation Function (ACF) plot of in-sample data after the first differencing ( $5 \%$ significance limits)

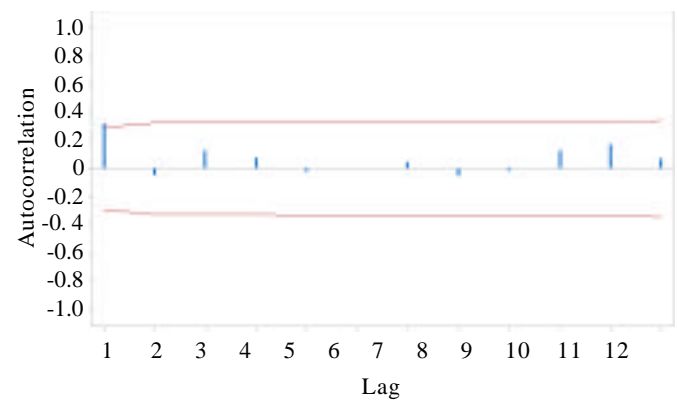

Fig. 4: ACF plot of in-sample data after stationary ( $5 \%$ significance limits)

After the data is stationary on variance and mean, then the model identification is based on correlogram analysis through $\mathrm{ACF}$ and $\mathrm{PACF}$ plots on the stationary data. The following are the results of the ACF and PACF plots on in-sample data that have been stationary against variance and mean.

From the $\mathrm{ACF}$ and PACF plots, the order of the ARIMA Model can be determined based on significant autocorrelation and partial autocorrelation (out of the confidence limit) which will be used as a general model. In the ACF plot in Fig. 4, it can be seen that the autocorrelation is only significant in the first lag, so that, it can be determined that q order is 1 . Whereas in the PACF plot in Fig. 5, it can be seen that partial autocorrelation is only significant in the first lag, so that, it can be determined that p-order is 1 . Previously, the first differencing has been carried out to achieve stationary in mean of in-sample data, so that, it can be determined that $\mathrm{d}$-order is 1 . Thus, the general model that be obtained is ARIMA $(1,1,1)$. By using the ARIMA $(1,1,1)$ model as a benchmark, some tentative models can be determined including ARIMA $(1,1,0)$ and ARIMA $(0,1,1)$. The next step is to estimate the parameters in the three models.

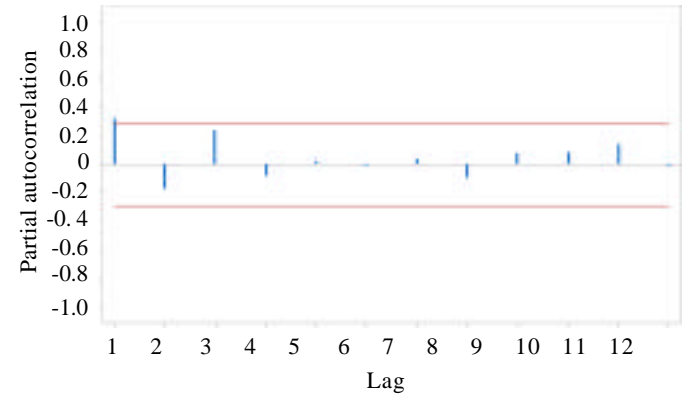

Fig. 5: PACF plot of in-sample data after stationary ( $5 \%$ significance limits)

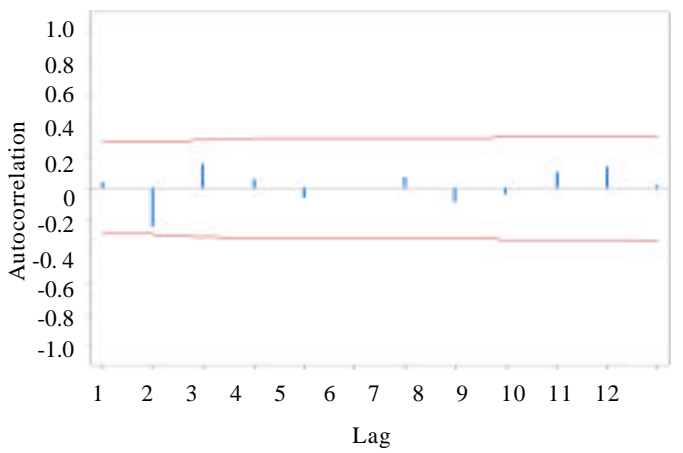

Fig. 6: Plot ACF of residual for ARIMA Model $(1,1,0$ with $5 \%$ significance limits)

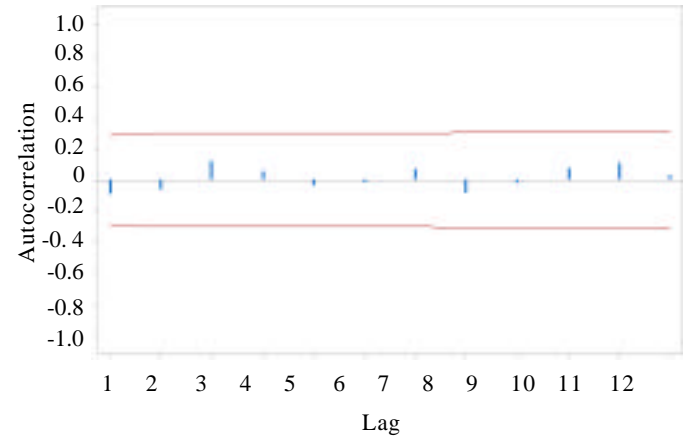

Fig. 7: Plot ACF of residual for ARIMA Model $(0,1,1$ with $5 \%$ significance limits for the autocorrelations)

There are several ways that can be used to estimate parameters in the ARIMA Model, one of the methods that can be used is the maximum likelihood method. After estimating the parameters in the ARIMA Model, the parameter significance testing for the three models is conducted using the t-test. The following are the results of the estimation and parameter significance testing for all tentative models based on the general ARIMA $(1,1,1)$ Model (Fig. 5-7). 


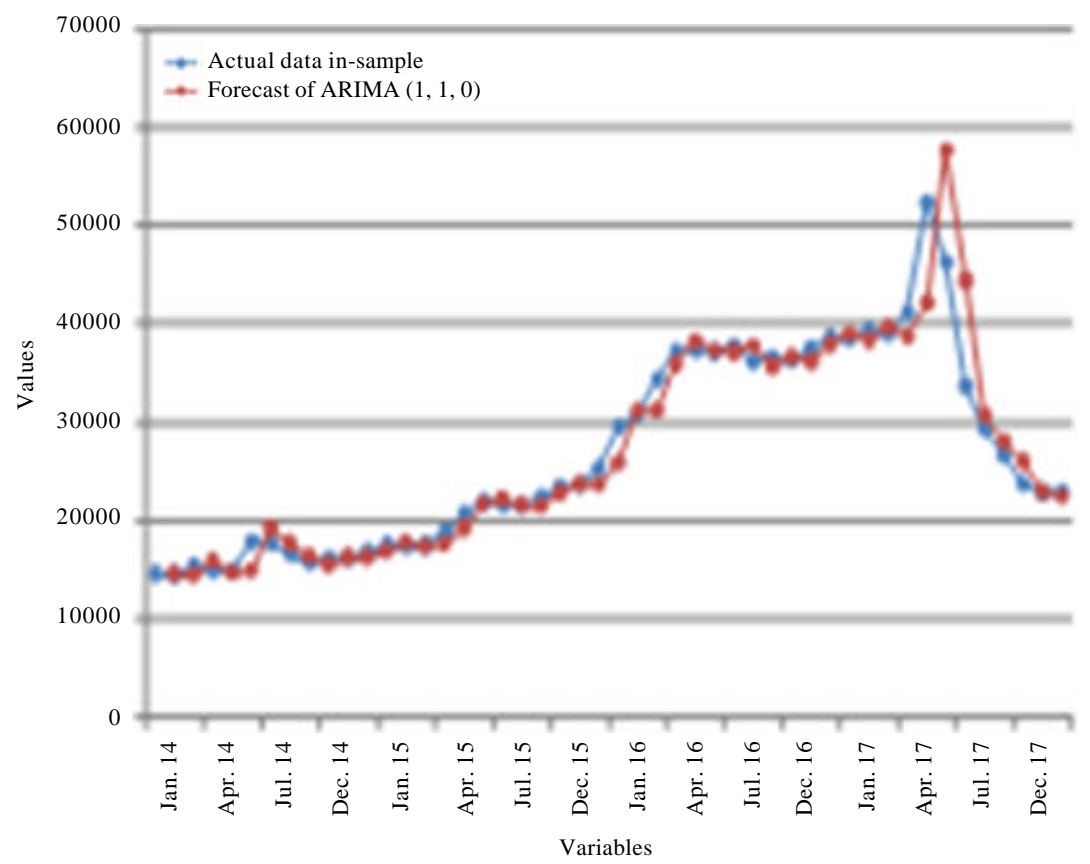

Fig. 8: Comparison curve between actual in-sample data and ARIMA prediction results $(1,1,0)$

\begin{tabular}{|c|c|c|c|c|}
\hline $\begin{array}{l}\text { Model } \\
\text { ARIMA }\end{array}$ & $\begin{array}{l}\text { Estimation } \\
\text { of parameters }\end{array}$ & t-stat. & $\mathrm{p}$-values & $\begin{array}{l}\text { Model } \\
\text { feasibility }\end{array}$ \\
\hline $\operatorname{ARIMA}(1,1,1)$ & $\begin{array}{l}\hat{\phi}_{1}=-0.2164 \\
\hat{\theta}_{1}=-0.7029\end{array}$ & $\begin{array}{l}-0.86 \\
-3.82\end{array}$ & $\begin{array}{l}0.397 \\
0.000^{* *}\end{array}$ & not feasible \\
\hline $\begin{array}{l}\operatorname{ARIMA}(1,1,0) \\
\operatorname{ARIMA}(0,1,1)\end{array}$ & $\begin{array}{l}\hat{\phi}_{1}=0.3457 \\
\hat{\theta}=-0.5582\end{array}$ & $\begin{array}{l}2.50 \\
-4.57\end{array}$ & $\begin{array}{l}0.016^{*} \\
0.000^{* *}\end{array}$ & $\begin{array}{l}\text { feasible } \\
\text { feasible }\end{array}$ \\
\hline
\end{tabular}

Based on the results of parameter significance testing in Table 2, two models with all the significant parameters are ARIMA $(1,1,0)$ and $\operatorname{ARIMA}(0,1,1)$. A model that is feasible to use in forecasting is a model with all significant parameters. Therefore, the ARIMA Model $(1,1,1)$ is eliminated from the selection of models that are suitable for use in forecasting.

Diagnostic testing is carried out on the resulting residuals and is useful to determine the feasibility of the models, so that, the model obtained is capable/feasible to be used in forecasting. A model is said to be feasible for forecasting, if it produces uncorrelated residuals. Diagnostic testing is carried out by identifying the ACF residuals plot. The residuals of models that are suitable for forecasting are white noise with the characteristics of not having a significant autocorrelation (out of the confidence limit) on the ACF plot. The following is an $\mathrm{ACF}$ plot against the residuals of the model that has been feasible, according to the Ljung-Box test, namely the $\operatorname{ARIMA}(1,1,0)$ and ARIMA $(0,1,1)$ Models.

In both of Fig. 6 and 7, it can be seen that there is not significant autocorrelation (out of the confidence limit) in the ACF plot of the residual generated by the ARIMA ( 1 , $1,0)$ and ARIMA $(0,1,1)$ models. Thus, it can be concluded that the ARIMA $(1,1,0)$ and $\operatorname{ARIMA}(0,1,1)$ Models are suitable for forecasting because they can produce white noise.

Based on the diagnostic test of model, it can be concluded that the ARIMA $(1,1,0)$ and $\operatorname{ARIMA}(0,1,1)$ Models are models that are suitable for using in forecasting. Furthermore, one of the two models will be chosen as the best model using the Mean Squared Error (MSE) indicator. The MSE value for the ARIMA Model $(1,1,0)$ is $8.72 \times 10^{-12}$ and the MSE value for the ARIMA $(0$, $1,1)$ Model is $8.04 \times 10^{-12}$ which both models have MSE values close to zero. The model chosen as the best model is $\operatorname{ARIMA}(1,1,0)$ which is the simpler one.

The performance of ARIMA Model $(1,1,0)$ in predicting in-sample data (the average price of garlic in Indonesia from January 2014 to December 2017) is presented graphically in Fig. 8 and the coefficient of determination is calculated. A model has a high accuracy because the model produces the small gaps which the predicted valuesare very close to the actual values. Figure 8 is a comparison between the actual in-sample data and the predicted values using the ARIMA Model $(1,1,0)$.

In Fig. 8, it can be seen that the prediction curve uses ARIMA $(1,1,0)$ and the actual in-sample curve is very close, so that, it can be indicated that the $\operatorname{ARIMA}(1,1,0)$ 
Table 3: Results of forecasting out-sample data with the ARIMA

\begin{tabular}{|c|c|c|c|}
\hline \multicolumn{4}{|c|}{ Model $(1,1,0)$} \\
\hline Date & Actual & Predicted & Residual \\
\hline Jan. 18 & 23150.380 & 23108.622 & 41.758 \\
\hline Feb. 18 & 26737.115 & 23127.062 & 3610.053 \\
\hline Mar. 18 & 30575.052 & 23133.445 & 7441.608 \\
\hline Apr. 18 & 33079.374 & 23135.652 & 9943.722 \\
\hline May 18 & 27966.033 & 23136.416 & 4829.618 \\
\hline Jun. 18 & 27669.457 & 23136.680 & 4532.778 \\
\hline
\end{tabular}

model can predict in-sample data (average price of garlic in Indonesia from January 2014 to December 2017) is quite accurate. This is supported also, by the coefficient of determination $\left(\mathrm{R}^{2}\right)$ of the ARIMA $(1,1,0)$ Model of 0.914 or $91.4 \%$ which means that $91.4 \%$ of the total diversity of in-sample data can be explained by the $\operatorname{ARIMA}(1,1,0)$ Model. The results of the forecast of the average price of garlic in Indonesia from January 2018 to June 2018 using the ARIMA (1.1.0) Model can be seen in Table 3.

The ARIMA $(1,1,0)$ Model produces out-sample forecasts that tend to be constant and produces a large enough residual, so that, it is less precise or less accurate in forecasting out-sample data. The coefficient of determination $\left(\mathrm{R}^{2}\right)$ of out-sample data is $59.8 \%$ which means that $59.8 \%$ of the total diversity of out-sample data can be explained by the ARIMA (1.1.0) Model while the remaining $40.2 \%$ caused by other factors that are not taken into account in the model. Thus, the ARIMA $(1,1$, 0) Model is a good enough model to be used in forecasting the average price of garlic in Indonesia because it produces a fairly high determination coefficient of $59.8 \%$.

\section{CONCLUSION}

The best model for predicting the average price of garlic in Indonesia is the ARIMA $(1,1,0)$ Model which can produce a small MSE value (close to 0 ) and produce a high determination coefficient $\left(\mathrm{R}^{2}\right)$ equal to $91.4 \%$ in predicting in-sample data. The following is equation of the $\operatorname{ARIMA}(1,1,0)$ Model produced:

$$
\begin{aligned}
\mathrm{Y}_{\mathrm{t}}^{*} & =\left(1+\phi_{1}\right) \mathrm{Y}_{\mathrm{t}-1}^{*}-\phi_{1} \mathrm{Y}_{\mathrm{t}-2}^{*}+\alpha_{\mathrm{t}} \\
& =(1+0.3457) \mathrm{Y}_{\mathrm{t}-1}^{*}-0.3457 \mathrm{Y}_{\mathrm{t}-2}^{*}+\alpha_{\mathrm{t}}
\end{aligned}
$$

Based on equation, it is known that the average price of garlic in Indonesia on the current month was influenced by the average price of garlic in Indonesia of the previous 1 month and the previous 2 months. Although, it cannot produce accurate predictions, the $\operatorname{ARIMA}(1,1,0)$ Model can produce a coefficient of determination $\left(\mathrm{R}^{2}\right)$ of $59.8 \%$ in forecasting out-sample data. The $\mathrm{R}^{2}$ yielded in forecasting out-sample data is not as high as the $\mathrm{R}^{2}$ yielded in predicting in-sample data. Therefore, it can be concluded that a model that produces a high measure of accuracy in predicting in-sample data will not necessarily produce a high measure of accuracy in forecasting out-sample data.

\section{ACKNOWLEDGEMENT}

The researchers gratefully acknowledge the support of the Department of Mathematics, Faculty of Mathematics and Natural Sciences, University of Brawijaya.

\section{REFERENCES}

Anonymous, 2017. Performance report of the directorate of basic goods and important goods in 2016. Ministry of Trade of the Republic of Indonesia, Jakarta, Indonesia.

Anonymous, 2018. Duties, functions and organizational structure of the directorate general of domestic trade. Ministry of Trade of the Republic of Indonesia, Jakarta, Indonesia.

Cryer, D. and J.C. Kung-Sik, 2008. Time Series Analysis: With Applications in R. 2nd Edn., Springer, New York, USA., ISBN-13: 9780387759586, Pages: 491.

Handoyo, S. and M. Marji, 2018. The fuzzy inference system with least square optimization for time series forecasting. Indonesian J. Elec. Eng. Comput. Sci., 11: 1015-1026.

Handoyo, S., A. Efendi, F. Jie and A. Widodo, 2017. Implementation of Particle Swarm Optimization(PSO) algorithm for estimating parameter of arma model via maximum likelihood method. Far East J. Math. Sci., 102: 1337-1363.

Ho, S.L., M. Xie and T.N. Goh, 2002. A comparative study of neural network and Box-Jenkins ARIMA modeling in time series prediction. Comput. Ind. Eng., 42: 371-375.

Hua, G.B. and T.H. Pin, 2000. Forecasting construction industry demand, price and productivity in Singapore: The BoxJenkins approach. Constr. Manage. Econ., 18: 607-618.

Kusdarwati, H. and S. Handoyo, 2018. System for prediction of non stationary time series based on the wavelet radial bases function neural network model. Intl. J. Electr. Comput. Eng., 8: 2327-2337.

Rojas, I., O. Valenzuela, F. Rojas, A. Guillen and L.J. Herrera et al., 2008. Soft-computing techniques and ARMA model for time series prediction. Neurocomputing, 71: 519-537. 
Tan, Z., J. Zhang, J. Wang and J. Xu, 2010. Day-ahead electricity price forecasting using wavelet transform combined with ARIMA and GARCH models. Applied Energy, 87: 3606-3610.

Wang, W.C., K.W. Chau, D.M. Xu and X.Y. Chen, 2015. Improving forecasting accuracy of annual runoff time series using ARIMA based on EEMD decomposition. Water Resour. Manage., 29: 2655-2675.
Wei, W.W., 2006. Time Series Analysis. In: The Oxford Handbook of Quantitative Methods in Psychology, Little, T.D. (Ed.). Oxford University Press, Oxford, UK., ISBN: 9780199934898 , pp: 458-485.

Zhang, G.P., 2003. Time series forecasting using a hybrid arima and neural network model. Neurocomputing, 50: $159-175$. 